\title{
Does Somatostatin in Each Organ Act Specifically on That Particular Organ?
}

\author{
Yukio Yamada, Seiki Ito, Ryo Kayamori, Yoichi Iwasaki, \\ Akira Shibata, Yoshinori Nara,* Masashi Suzuki and \\ Yoshinei Hirasawa* \\ The First Department of Internal Medicine, Niigata University \\ School of Medicine and *Shinrakuen Hospital, Niigata 951
}

\begin{abstract}
Yamada, Y., Itro, S., KaYamori, R., Iwasaki, Y., Shibata, A., Nara, Y., SuzukI, M. and Hirasawa, Y. Does Somatostatin in Each Organ Act Specifically on That Particular Organ? Tohoku J. exp. Med., 1979, 129 (1), 101-102 Rats with hypercalcemia induced by injection of vitamin $D_{2}$ had a decreased thyroid somatostatin content, whereas the somatostatin content in their pancreas was almost within the normal range. This suggests that somatostatin in different organs acts specifically on each particular organ as a local hormone or hormonelike substance. - somatostatin; thyroid; pancreas; local hormone; vitamin $\mathrm{D}_{\mathbf{2}}$
\end{abstract}

Somatostatin (growth hormone release-inhibiting factor) exists in various organs such as the hypothalamus, central nervous system, thyroid, gastro-intestinal tract and pancreas (Arimura et al. 1975; Hökfelt et al. 1975). This study was performed in order to investigate if somatostatin in different organs responds concurrently and uniformly to a given stimulus.

\section{Materials and Methods}

Eight male Wistar strain rats weighing 200 to $250 \mathrm{~g}$ were given vitamin $\mathrm{D}_{2}(200,000$ units/day, Ergocalciferol, Eisai, Japan) by daily subcutaneous injections for 17 days. They were decapitated, together with eight control rats which had had no injection, and their thyroid and pancreas were removed. The thyroid and pancreas were extracted by use of $1 \mathrm{~N}$ acetic acid and the extracts were boiled, rapidly chilled and centrifuged and the supernatants were lyophilized. The residues were dissolved in $0.05 \mathrm{M}$ veronal buffer ( $\mathrm{pH}$ 7.5) and measured for somatostatin and calcitonin (CT) contents by radioimmunoassay. Antisera against somatostatin and CT were prepared by injections of synthetic somatostatin or human CT (Peptide Institute, Osaka, Japan) conjugated to bovine serum albumin using glutaraldehyde.

\section{Results and Discussion}

In our study, injection of vitamin $\mathrm{D}_{2}$ into rats induced a remarkable rise of the serum calcium level (from $9.9 \pm 0.9$ to $15.5 \pm 1.8 \mathrm{mg} / 100 \mathrm{ml}$ ) and a remarkable decrease of thyroid somatostatin content as compared with the corresponding values in control animals $(p<0.01)$. On the other hand, in the pancreatic somatostatin content there was almost no difference between the vitamin $D_{2}$-treated and control rats (Fig. 1). This finding

Received for publication, January 8, 1979.

Requests for reprints should be addressed to: Dr. Yukio Yamada, Shinrakuen Hospital, Nishiariakecho 1-27, Niigatashi 951, Japan. 


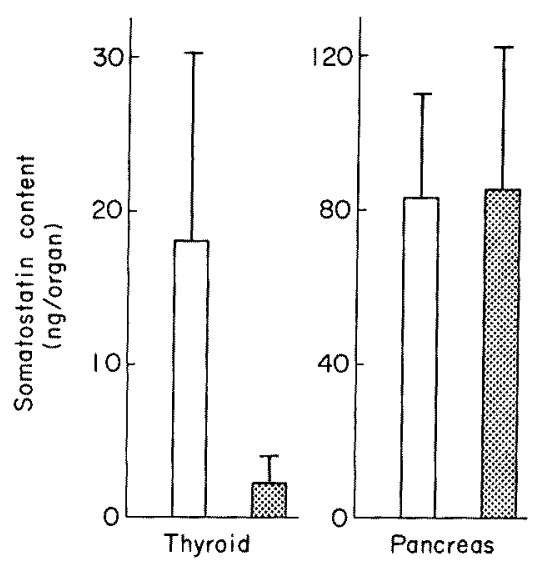

Fig. 1. Effect of vitamin $\mathrm{D}_{2}$ on the rat thyroid and pancreatic somatostatin contents.

The bars indicate mean \pm S.E.M. $\square$, control rats; $\ldots$, vitamin $D_{2}$ injected rats.

indicates that the thyroid somatostatin and the pancreas somatostatin do not concurrently or uniformly respond to a given stimulus, which suggests that somatostatin in different organs acts specifically on each particular organ as a local hormone or hormone-like substance.

\section{References}

1) Arimura, A., Sato, H., Coy, D.H. \& Schally, A.V. (1975) Radioimmunoassay for GH. release inhibiting hormone. Proc. Soc. exp. Biol. Med., 148, 784-789.

2) Hökfelt, T., Efendic, S., Hellerström, C., Johansson, O,, Luft, R. \& Arimura, A. (1975) Cellular localization of somatostatin in endocrine-like cells and neurons of the rat with special references to the $A_{1}$-cells of the pancreatic islets and to the hypothalamus. Acta endocr., 80, Suppl. 200, 5-4l. 